University of Nebraska - Lincoln

DigitalCommons@University of Nebraska - Lincoln

\title{
Test-retest reliability and minimal detectable change of the computerized dynamic posturography PROPRIO for adults with chronic traumatic brain injury
}

\author{
Guilherme Manna Cesar \\ Madonna Rehabilitation Hospitals, g.cesar@unf.edu \\ Thad W. Buster \\ Madonna Rehabilitation Hospitals \\ Judith M. Burnfield \\ University of Nebraska-Lincoln, jburnfield@madonna.org
}

Follow this and additional works at: https://digitalcommons.unl.edu/mechengfacpub

Part of the Analytical, Diagnostic and Therapeutic Techniques and Equipment Commons, Other Engineering Science and Materials Commons, and the Other Mechanical Engineering Commons

Cesar, Guilherme Manna; Buster, Thad W.; and Burnfield, Judith M., "Test-retest reliability and minimal detectable change of the computerized dynamic posturography PROPRIO for adults with chronic traumatic brain injury" (2021). Mechanical \& Materials Engineering Faculty Publications. 594.

https://digitalcommons.unl.edu/mechengfacpub/594

This Article is brought to you for free and open access by the Mechanical \& Materials Engineering, Department of at DigitalCommons@University of Nebraska - Lincoln. It has been accepted for inclusion in Mechanical \& Materials Engineering Faculty Publications by an authorized administrator of DigitalCommons@University of Nebraska Lincoln. 


\title{
Test-retest reliability and minimal detectable change of the computerized dynamic posturography PROPRIO for adults with chronic traumatic brain injury
}

\author{
Guilherme M. Cesar, ${ }^{1}$ Thad W. Buster, ${ }^{1}$ \\ and Judith M. Burnfield ${ }^{1,2}$
}

\footnotetext{
1 Institute for Rehabilitation Science and Engineering, Madonna Rehabilitation Hospitals, Lincoln, NE, USA

2 University of Nebraska-Lincoln, Lincoln, NE, USA

Correspondence — Guilherme M. Cesar gcesar@madonna.org Institute for Rehabilitation Science and Engineering, Madonna Rehabilitation Hospitals, 5401 South Street, Lincoln, NE, 68506-2150, USA

ORCID

Guilherme M. Cesar http://orcid.org/0000-0002-5596-9439

Thad W. Buster http://orcid.org/0000-0001-7454-1748

Judith M. Burnfield http://orcid.org/0000-0001-6184-5179
}

Published in Disability and Rehabilitation 43:14 (2021), pp 2038-2044.

doi:10.1080/09638288.2019.1688872

Copyright (c) 2019 Informa UK Limited, trading as Taylor \& Francis Group. Used by permission.

Submitted 30 May 2019; revised 25 September 2019; accepted 31 October 2019; published 14 November 2019.

Suggested citation — Guilherme M. Cesar, Thad W. Buster, \& Judith M. Burnfield (2021) Test-retest reliability and minimal detectable change of the computerized dynamic posturography PROPRIO for adults with chronic traumatic brain injury, Disability and Rehabilitation, 43:14, 2038-2044, DOI: 10.1080/09638288.2019.1688872 


\section{Abstract}

Purpose: Balance deficits after brain injury, including reactive recovery from unexpected perturbations, can persist well after rehabilitation is concluded. While traditional clinical assessments are practical, the anticipatory nature of the tasks may mask perceptible balance control. Computerized dynamic posturography can directly quantify capacity to respond to unexpected, external perturbations. This study examined the reliability of the computerized dynamic posturography assessment with the device PROPRIO ${ }^{\circledR} 4000$ in adults with traumatic brain injury and created the minimal detectable change for its standardized test.

Methods: Ten adults (ages 21-55 years) with chronic (average $10 \pm 6$ years postinjury) severe (loss of consciousness 2-75 days) brain injury performed three trials of the Propriotest ${ }^{\circledR}$ on two separate days. The average of three trials and the best scores were used separately for analysis. Test-retest reliability was verified using Intraclass Correlation Coefficients with 95\% confidence interval and standard error of measurement in relation to the Intraclass Correlation Coefficients at $95 \%$. The minimal detectable change was calculated at $95 \%$ confidence level (minimal detectable change ${ }_{95}$ ) and Bland-Altman plots were created to express agreement between measurement days.

Results: The results exhibited excellent reliability for both average (Intraclass Correlation Coefficient of 0.969, standard error of measurement 50.9 points) and best (Intraclass Correlation Coefficient of 0.985 , standard error of measurement 31.3 points) scores, with average and best minimal detectable change ${ }_{95}$ of 141.0 and 86.7 points, respectively.

Conclusions: Clinicians and rehabilitation researchers can use these findings to determine if a Propriotest ${ }^{\circledR}$ change score represents a true post-treatment effect with adults with chronic brain injury.

\section{Implications for rehabilitation}

- After brain injury, balance deficits are common and can persist well after completion of rehabilitation programs.

- Computerized dynamic posturography allows for objective quantification of one's capacity to respond to external perturbations.

- The device PROPRIO ${ }^{\circledR} 4000$ provides reliable quantification of balance deficits of community dwelling individuals who have experienced a severe traumatic brain injury.

- The minimal detectable change scores created can assist clinicians and rehabilitation researchers detect whether a change in balance score represents a true effect of an intervention at posttreatment.

Keywords: Balance, minimal detectable change, reliability, computerized dynamic posturography, rehabilitation, brain injury 


\section{Introduction}

Balance deficits are common after brain injury (BI) and can persist well after rehabilitation is concluded [1,2]. Balance, defined as the ability to maintain a state of equilibrium between the projection of the center of mass and the base of support [3], is a critical element of independence in daily functional mobility $[4,5]$. Intact visual, vestibular, and somatosensory systems collectively modulate balance requirements of motor skills, including appropriate reactive recovery from unexpected perturbations (e.g., tripping, physical contacted in crowded environments) [6]. Disruption of any of these systems can impact reactive balance responses, increasing risk of falls and limiting engagement in many life activities $[7,8]$.

Quantification of reactive balance allows clinicians to determine whether individuals' responses meet the demands of independent mobility $[9,10]$. While traditional clinical balance assessments are practical, the anticipatory nature of the tasks may mask perceptible balance control. For example, individuals may adjust their motor responses (e.g., modify their trunk position before lifting their foot to a stool) as the amplitude of the self-imposed perturbation needed to achieve the task is known. Since rehabilitation progression is based on quantifiable improvements, the ability to reliably detect changes in reactive balance performance is imperative for clinical management and decision making.

Technological advancements in assessment devices have created opportunities to more objectively quantify an individual's capacity to respond to balance perturbations. Static posturography is a technique that evaluates postural control while individuals maintain quiet stance on a fixed support surface. This approach typically uses force plates and measures derived from center of pressure excursions to detect postural control responses in individuals with $[11,12]$ and without disabilities $[13,14]$. The perturbation arises, in part, from the individual's self-generated muscle responses aimed at maintaining balance in the presence of changing sensorial input (e.g., visual, vestibular, or somatosensory) [15]. Continuous corrective movements are required to maintain upright stance, which can be taxing particularly for those with weakness, or challenges with their visual, vestibular or somatosensory systems. In contrast to evaluations that use static support 
surfaces, computerized dynamic posturography (CDP) utilizes predetermined motions of the supporting surface (platform) to quantify an individual's balance deficits. The PROPRIO ${ }^{\circledR} 4000$ (Perry Dynamics, Decatur, IL) is a portable CDP device that generates random perturbations that vary in direction, speed and amplitude. The random nature of the platform perturbations is expected to challenge reactive balance responses rather than the planned, anticipatory postural adjustments observed during traditional clinical tests.

While the validity of CDP [16] and its effectiveness for detecting balance deficits [17] have been demonstrated, the parameters needed to advance its clinical use such as responsiveness and minimal detectable change (MDC) for the PROPRIO ${ }^{\circledR} 4000$ and its assessment tool Propriotest ${ }^{\circledR}$ for adults with BI have not been evaluated. Therefore, the purpose of this study was to examine the test-retest reliability and to develop the MDC score for the PROPRIO ${ }^{\circledR} 4000$ Propriotest ${ }^{\circledR}$ for adults who have experienced a severe traumatic BI. We hypothesized that the test-retest reliability would be acceptable and high based on prior studies utilizing repeated measures with this technology [16-18].

\section{Methods}

\section{Participants}

Ten individuals with chronic and severe (defined as loss of consciousness for longer than 24 h, or a Glasgow Coma Score of 8 or less) traumatic $\mathrm{BI}$ participated in this study. The inclusion criteria included individuals who were nine months or greater post-injury, no history of major cardiovascular diseases (e.g., myocardial infarction, heart failure), Functional Independence Measure locomotion score of $\geq 5$, not receiving inpatient/outpatient care, and classified as 6 or greater on the Rancho Los Amigos Levels of Cognitive Functioning Scale [19] at the time of participation. The duration of loss of consciousness following the injury was used as the measure of severity of BI since initial Glasgow Coma Scale values were not available for many participants.

Table 1 is organized based on the loss of consciousness measure and presents each participant's individual characteristics. 
Table 1. Study population characteristics.

\begin{tabular}{|c|c|c|c|c|c|c|c|c|c|c|}
\hline Participant & $\begin{array}{l}\text { LOC } \\
\text { (days ) }\end{array}$ & Sex & $\begin{array}{l}\text { Age } \\
\text { (years) }\end{array}$ & $\begin{array}{l}\text { Height } \\
\text { (m) }\end{array}$ & $\begin{array}{l}\text { Weight } \\
(\mathrm{kg})\end{array}$ & BMI (\%) & $A B C(\%)$ & $\mathrm{DHI}$ & BBS & DGI \\
\hline 1 & 75 & M & 24 & 1.70 & 74.5 & 25.7 & 100 & 6 & 53 & 21 \\
\hline 2 & 49 & $\mathrm{~F}$ & 46 & 1.71 & 56.4 & 19.2 & 48 & 22 & 46 & 19 \\
\hline 3 & 35 & M & 21 & 1.91 & 92.3 & 25.4 & 91 & 12 & 54 & 19 \\
\hline 4 & 21 & $\mathrm{~F}$ & 28 & 1.82 & 70.2 & 21.3 & 76 & 12 & 50 & 22 \\
\hline 5 & 14 & $\mathrm{~F}$ & 26 & 1.64 & 55.8 & 20.8 & 87 & 22 & 56 & 22 \\
\hline 6 & 14 & M & 24 & 1.75 & 72.7 & 23.7 & 82 & 18 & 45 & 19 \\
\hline 7 & 11 & $\mathrm{~F}$ & 40 & 1.65 & 69.0 & 25.3 & 88 & 10 & 56 & 24 \\
\hline 8 & 7 & M & 53 & 1.78 & 72.7 & 23.0 & 94 & 18 & 56 & 23 \\
\hline 9 & 4 & M & 38 & 1.83 & 95.0 & 28.4 & 100 & 0 & 56 & 23 \\
\hline 10 & 2 & $\mathrm{~F}$ & 55 & 1.70 & 75.5 & 26.1 & 96 & 0 & 56 & 23 \\
\hline
\end{tabular}

BMI: body mass index; LOC: loss of consciousness; ABC: activities specific balance confidence; DHI: dizziness handicap inventory; BBS: Berg balance scale; DGI: dynamic gait index; DMA: dynamic movement analysis.

\section{Instrumentation}

Participants' CDP responses were detected with the PROPRIO ${ }^{\circledR} 4000$ Reactive Balance System (Perry Dynamics, Decatur, IL) (Figure 1). The device consisted of a computer-controlled 28-inch diameter platform that tilts up to $14^{\circ}$ multi-directionally (lateral, anterior, posterior) at $6-60^{\circ}$ per second. The system utilizes ultrasonic technology (sampling frequency of $4 \mathrm{~Hz}$ ) to track the movement of a transmitter to quantify the motion of the participants' estimated center of mass. A harness (SafeLight Universal 3M 10910, St. Paul, MN) was used to protect against falls during the tests.

\section{Protocol}

Participants were scheduled for three separate sessions spaced between 24 and $72 \mathrm{~h}$ apart. During the first visit, participants completed the institutional review board's approved informed consent document and a medical history questionnaire that included information about the nature of their injuries (e.g., length of time since injury, duration of loss of consciousness, residual disability). In addition, anthropometric data were collected followed by the Activities Specific Balance Confidence Scale and the Dizziness Handicap Inventory to quantify the 
(A)

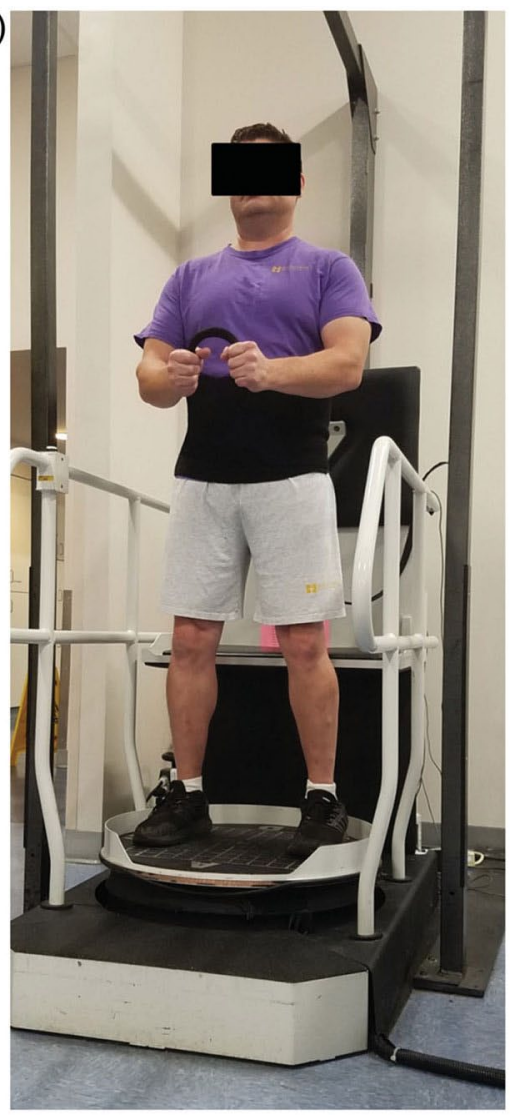

(B)

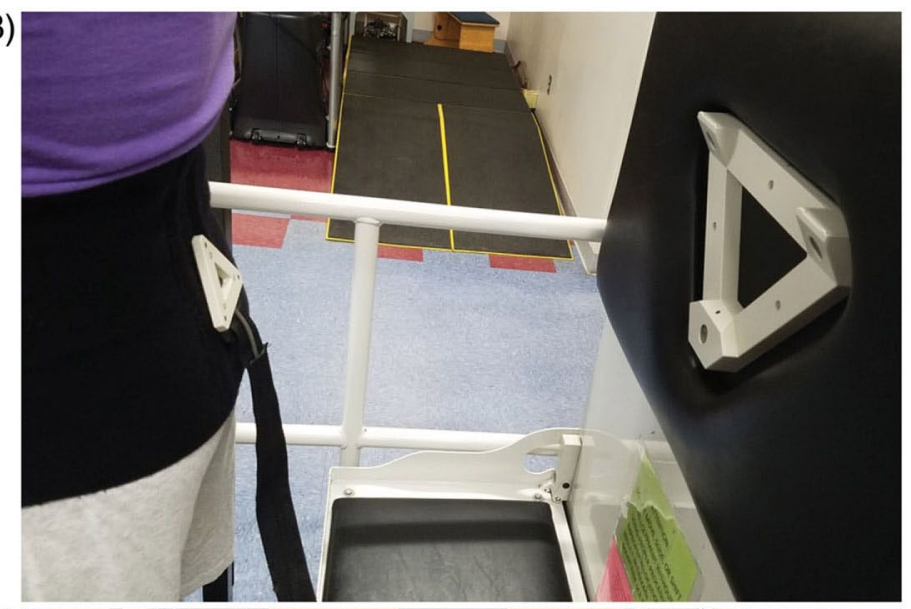

(C)

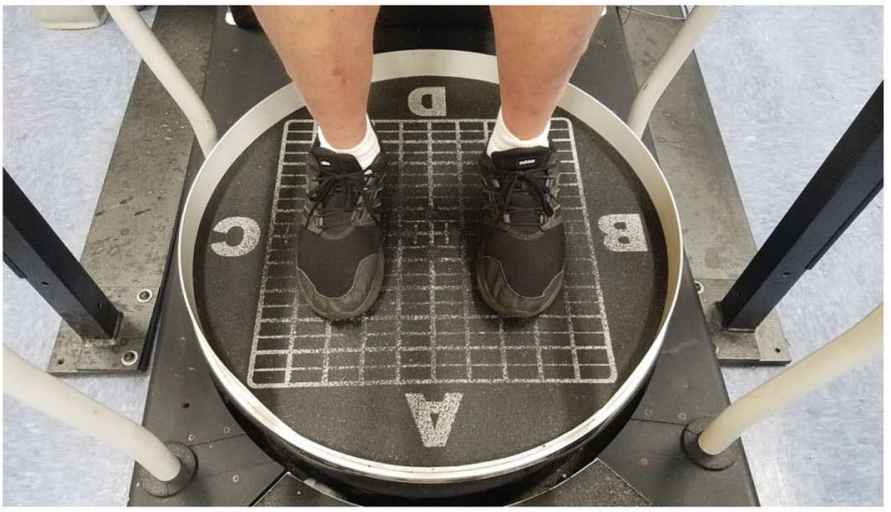

Figure 1. An individual on the device Proprio ${ }^{\circledR} 4000$ simulating the computerized dynamic posturography Propriotest ${ }^{\circledR}$. Participants were instructed to look straight ahead while holding a short piece of rope between their two hands with their elbows flexed at a $90^{\circ}$ angle (A). As the platform delivered progressively greater amplitudes of perturbation, participants attempted to maintain balance by minimizing trunk movement and the consequent motion of the ultrasound sensor placed at the level of their estimated center of mass (B). For the standardized test, the outside borders of participants' feet were aligned with the fourth gridline from the center of the platform and the anterior-posterior center line was aligned with the middle of their feet (C).

participants' self-reported perceptions of balance [20]. Participants' balance abilities were assessed using two common standardized clinical tests, the Berg Balance Scale and the Dynamic Gait Index. The same researcher administered all balance assessments in the same order to all participants using standardized procedures described in the literature $[21,22]$. In this session, participants were also introduced to the CDP system's standardized balance test (Propriotest ${ }^{\circledR}$ ) and performed the test for familiarization. 
During the next two sessions, participants performed the Propriotest ${ }^{\circledR}$. Although a fall-arresting harness was used to reduce risk of injury in the event of a fall, utmost care was taken to ensure that no tension was applied to the harness during the test. In accordance with the manufacturer's recommendations, the system's ultrasound transmitter was positioned between the participants' posterior superior iliac spines on a Velcro band that was placed around the waist of the participants (Figure 1(B)). Participants were instructed to place the outside border of their feet on the 4th gridline from the center of the platform (medial-lateral direction) and the anterior-posterior center line crossed through the middle of their feet (Figure 1(C)). Participants looked straight ahead while keeping their heads up and holding a short piece of rope between their two hands with their elbows flexed at a $90^{\circ}$ angle (Figure $1(\mathrm{~A})$ ). Participants were instructed that the goal of the task was to minimize trunk movement and the consequent motion of the ultrasound sensor placed between their posterior superior iliac spines. The test initiated with small arcs of platform motion at slow speeds followed by progressively greater amplitudes of perturbation (i.e., both degrees of tilt and velocity). Each Propriotest ${ }^{\circledR}$ lasted $120 \mathrm{~s}$ or until the ultrasound sensor located on the participant's back moved greater than three inches in the anterior-posterior, mediallateral or vertical plane. The test was performed three times each visit and participants rested as needed for up to 5 min between each test.

\section{Data analyses}

\section{Activities-Specific Balance Confidence}

The scoring for this self-report confidence measure of balance ability involves the averaging of 16 items ( $0-100 \%$ per item). The minimum and maximum scores are 0 and 1600, respectively, with lower scores indicating lower level of confidence in doing the activities without losing balance or becoming unsteady. Threshold scores for function have been stipulated as high level $(>80 \%)$, moderate level $(50-80 \%)$ and low level $(<50 \%)$ [23].

\section{Dizziness Handicap Inventory}

This 25-item self-assessment scale is composed of three subscales: a 9-item functional subscale, a 9-item emotional subscale, and a 7-item 
physical subscale. The responses available to the questions regarding the difficulties experienced because of dizziness are "always" (4 points), "sometimes" (2 points), or "no" (0 points). The minimum and maximum scores are 0 and 100, respectively, with lower scores indicating no perceived handicap.

\section{Berg Balance Scale}

The Berg Balance Scale includes 14 functional activities that involve the control of balance during sitting, standing, transferring, turning, stepping, reaching forward, and picking up an object from the floor. The items are graded on an ordinal 5-point scale from 0 (unable to perform) to 4 (perform without difficulty). The minimum and maximum BBS scores are 0 and 56, respectively, with lower scores indicating worse balance performance. The score of 45 or lower has been cited as a threshold for risk of falling for older adults [24].

\section{Dynamic Gait Index}

The Dynamic Gait Index [25] consists of eight walking task items (e.g., obstacle avoidance, pivoting, stair negotiation) that are scored on an ordinal 4-point scale from 0 (severe impairment) to 3 (no gait dysfunction). The minimum and maximum scores are 0 and 24, respectively, with lower scores indicating severe walking and balance impairment. Scores lower than or equal to 19 have been associated with increased risk of falling [26].

\section{Dynamic Movement Analysis}

The Dynamic Movement Analysis (DMA) score was represented by the sum of movement for all directions (anterior-posterior, mediallateral, vertical) recorded in inches by the device's ultrasound sensor throughout the 120-s test. If a participant was unable to complete the full 120-s test, the software generated an adjusted score by adding 12 points for every second remaining in the test. The DMA's minimum and maximum scores are 0 and 1440, respectively, with lower scores indicating better balance. The average of three trials (per assessment day) and the best scores (of each assessment day) were used separately for statistical treatment. 


\section{Statistical analyses}

Test-retest reliability

The two-way Intraclass Correlation Coefficient $\operatorname{ICC}_{(2,1)}$ type consistency) was calculated with a $95 \%$ confidence interval (ICC $\left.{ }_{95}\right)$ to analyze the test-retest reliability. ICC values can vary from 0 to 1 ; therefore, we considered values greater than 0.90 as excellent reliability, between 0.75 and 0.9 as good, between 0.5 and 0.75 as moderate, and values $<0.5$ as poor [27]. The standard error of measurement was calculated in relation to the $\mathrm{ICC}_{95}$ to represent the absolute reliability [28] and to describe the within-subject variability attributable to repeated measurements. The following equation was used to calculate the standard error of measurement: SEM $=\mathrm{SD} \times\left(1-\mathrm{ICC}_{95}\right)^{1 / 2}$. In this equation, SD represents the standard deviation of all observations.

\section{Minimal detectable change}

The MDC for the Propriotest ${ }^{\circledR}$ DMA scores was calculated with a confidence level of $95 \%\left(\mathrm{MDC}_{95}\right)$. The following equation was used: $\mathrm{MDC}_{95}$ $=\mathrm{SEM} \times 1.96 \times(2)^{1 / 2}$. In this equation, SEM is the standard error of measurement (equation described above), 1.96 is the z-score associated with the desired $95 \%$ confidence level, and the square root of 2 indicates the variance of 2 measurements. Bland-Altman plots were created for the representation of the between-session differences versus the mean value of the two sessions. This plot visually describes the agreement between two measurements, indicating good repeatability when $95 \%$ of the data points lie within two standard deviations (2SD) of the mean difference [29].

\section{Results}

Descriptive data from both average and best DMA scores are presented in Table 2. The Propriotest ${ }^{\circledR}$ assessment presented excellent test-retest reliability for both DMA scores (Table 2). In addition, the Bland-Altman plots visually verified the high level of agreement of DMA scores between the two assessment days. All but one data point, expressed as the ratio between measurements 
Table 2. Descriptive statistics, Intraclass Correlation Coefficient at $95 \%$ confidence interval $\left(\mathrm{ICC}_{95}\right), 95 \%$ confidence interval $(95 \% \mathrm{Cl})$, standard error of measurement $(\mathrm{SEM})$, and minimal detectable change at $95 \%$ confidence interval $\left(\mathrm{MDC}_{95}\right)$ for the average of three trials per test day (Average Scores) and the best score per test day (Best Scores) for the DMA results of all 10 participants performing the Propriotest ${ }^{\circledR}$.

$\frac{\text { Average scores }}{\text { Day } 1 \quad \text { Day } 2} \quad \frac{\text { Best scores }}{\text { Day } 1 \quad \text { Day } 2}$

\begin{tabular}{lcc}
\hline Average (SD) & $339(294) 349(300)$ & $288(266) 300(258)$ \\
Range & $140-1028134-985$ & $125-945127-927$ \\
SD & 289 & 255 \\
ICC $_{95}$ & 0.969 & 0.985 \\
$95 \% \mathrm{Cl}$ & $0.875<\mathrm{ICC}<0.992$ & $0.940<\mathrm{ICC}<0.996$ \\
SEM (points) & 50.9 & 31.3 \\
$\mathrm{MDC}_{95}$ (points) & 141.0 & 86.7 \\
\hline
\end{tabular}

(between-session differences versus the mean difference), were within 2SD of the mean [29,30], suggesting good repeatability of the Propriotest ${ }^{\circledR}$ (Figure 2 ).

AVERAGE SCORES

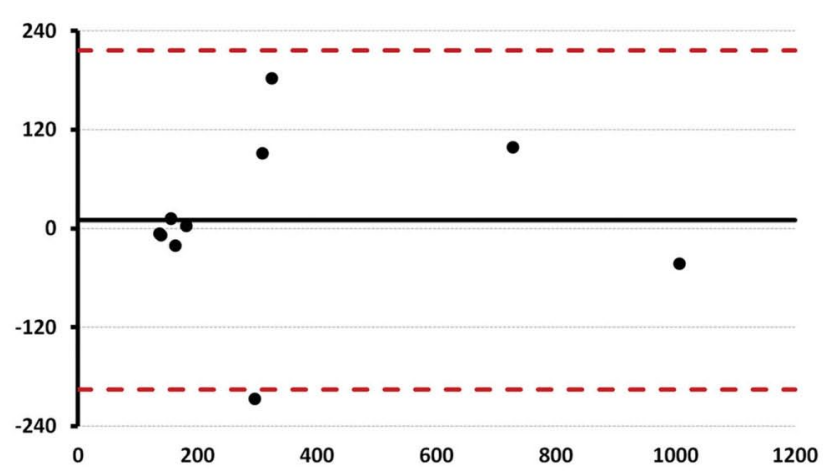

BEST SCORES

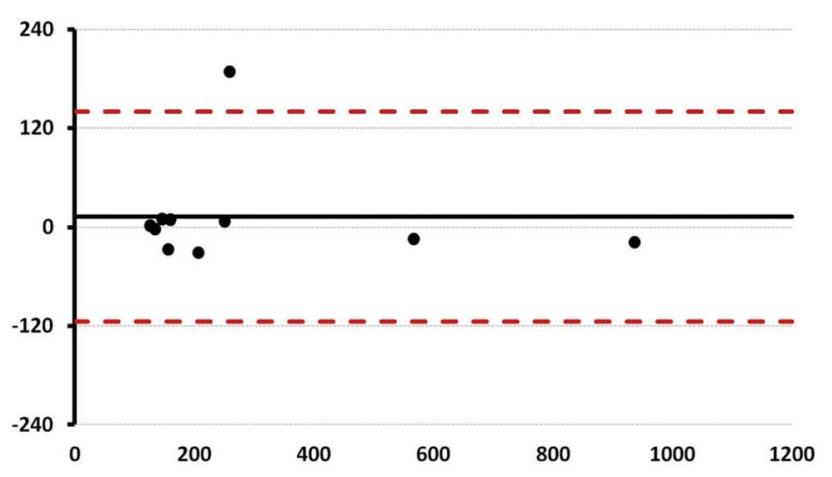

Figure 2. Bland-Altman plots for average (left) and best (right) DMA scores, representing the differences between scores from assessment Day 1 and Day 2 versus the average of the scores from both assessment days. For average and best DMA scores, all but one of the differences occurred between the expected limits of agreement $( \pm 2 \mathrm{SD})$, expressed as the red dashed lines within each plot. Both plots represent the calculated scores from all 10 participants with overlapping data points noted on the plot for average scores. Of note is the larger spread of values when analyzing the average scores compared with the best scores, indicating an expected larger variability in reactive balance responses when utilizing the patients' average scores. 


\section{Discussion}

Relying on trustworthy data is crucial in clinical practice to advance patients through rehabilitation accomplishments. Clinical and research settings currently employ both static [11-13,31-35] and dynamic $[17,18,36-40]$ posturography approaches, however, previously lacking were metrics for assessing the significance of changes in CDP scores while using the PROPRIO ${ }^{\circledR} 4000$. The narrow confidence intervals obtained in our study suggests that the CDP assessment conducted with the PROPRIO ${ }^{\circledR} 4000$ provides reliable measures of reactive balance for adults with chronic BI. In addition, the MDC created in the current work stipulates a benchmark for clinicians and rehabilitation researchers to interpret changes in DMA scores after balance-focused interventions for those who experienced $\mathrm{BI}$ and exhibit characteristics similar to the participants of our study.

In agreement with our hypothesis, the reliability of the CDP Propriotest ${ }^{\circledR}$ was high when administered to adults with chronic severe BI. While each trial presents a combination of unknown perturbations (direction, speed, amplitude) in a perceived random order, the findings of excellent reliability ( 0.969 for average score, 0.985 for best score) and narrow $\mathrm{Cl}$ ranges suggests that the reactive balance responses executed by our participants were consistent across testing days. In addition, the device reliably detected the participants' balance performances, even though factors within and across participants could have inflated score variability. Within each individual, factors that may have led to variations in DMA scores between trials and days included the random combination of direction and amplitude of perturbation experienced. For example, if an individual with pretibial muscle weakness could not maintain upright balance when reacting to a posterior platform tilt, the DMA score would be higher (i.e., worse score) if this perturbation was experienced earlier versus later into the Propriotest ${ }^{\circledR}$. In contrast, factors that likely contributed to variations in scores across individuals could have included the underlying neurophysiologic systems affected by the initial injury (e.g., vestibular, vision, proprioceptive, cognitive, motor). When generating a reactive response, each individual would be expected to respond differently to external perturbation given variations in processing time, reaction time, and/or movement time following the injury. 
In addition to providing support to the reliability of using the CDP PROPRIO $4000{ }^{\circledR}$, we developed the MDC score for the Propriotest ${ }^{\circledR}$ DMA. This threshold represents the smallest change in DMA score that is considered a real change rather than a change that can occur due to random measurement errors. Considering the total change in score (i.e. $100 \%$ ) of 1440 points available during the Propriotest ${ }^{\circledR}$, the MDC of 141.0 and 86.7 points represent a change in $9.8 \%$ and $6 \%$ for the average and best scores, respectively. These percent changes are similar to the changes reported with another CDP device in which young adults without disabilities underwent a sensory organization test [18]. Utilizing only Condition 4 ("eyes open, sway reference surface") from the sensory organization battery of balance tests, the change in score between sessions one and two was 3\%, with the MDC for the composite score of 8 points (or $8 \%$ ). Condition 4 of the sensory organization test was similar to the Propriotest ${ }^{\circledR}$ assessment. In contrast to the sensory organization test, the approach used in the current study when performing the standardized Propriotest ${ }^{\circledR}$ did not allow for the differentiation of input deficits (e.g., vestibular, proprioceptive, or visual). Future work could explore the impact of modifying sensorial input (e.g., eyes closed or use of foam) on reactive balance responses while using the PROPRIO ${ }^{\circledR} 4000$ to further distinguish contributions of balance deficits from specific systems.

The visualization of the MDC scores via the agreement between the two assessment sessions (Figure 2) provided an additional clinical interpretation. Although good repeatability was achieved with only one data point outside the stipulated two standard deviations for both average and best scores, the plots exhibited a larger spread of values (i.e., width between the boundaries) when using the average scores compared with the best scores. The $62 \%$ larger boundary width indicates greater variability in reactive balance performance when analyzing average versus best scores. Thus, clinicians can opt to use either the patient's actual balance capability represented by the peak balance performance (i.e., best score) or the patient's overall performance (i.e., average scores) to guide subsequent rehabilitation steps.

It is important to note that of the five participants who achieved the maximum score on the BBS (participants 5, 7-10), the best DMA scores ranged from 125 to 155 points. Similarly, of the four participants who achieved the score of 23 or the maximum 24 on the DGI (participants 
7-10), best DMA scores ranged from 133 to 155 points. While these scores represent the best reactive balance performance (i.e., lowest scores) from our group of participants, these scores still allow for additional means for quantifying deficits following a $\mathrm{BI}$ and documenting improvement in response to treatment-induced recovery. In contrast, this effect could not be observed with the clinical tests used in our study (i.e., ceiling effect) and it can pose a limitation to clinical assessments. When utilizing a tool for balance assessment of patient populations, it is important to adopt a tool that is sensitive to changes over time and has the potential to provide continuous measures [41].

\section{Clinical implications}

Increased risk of falls during community ambulation after completion of a $\mathrm{BI}$ rehabilitation program is related to poor balance scores obtained during standing tasks and postural control on an unstable surface [42]. Reliable quantification of reactive balance responses similar to the one presented in the current study is crucial to generate knowledge regarding potential for safe ambulation during community integration for individuals with $\mathrm{Bl}$. The excellent reliability observed with the Propriotest ${ }^{\circledR}$ when delivered to adults with chronic severe $\mathrm{BI}$ provides clinicians with an accurate tool to quantify an important aspect of functional independence in daily living. The current study should also inspire future work to create DMA MDC scores for individuals with $\mathrm{BI}$ undergoing inpatient and outpatient rehabilitation.

\section{Limitations}

The heterogeneity of functional outcomes after $\mathrm{BI}$ can promote a myriad of motor and balance limitations. The sample recruited and utilized in our study was relatively small and purposefully homogeneous in functional measures as it was drawn from a secondary analysis of an existing data set [17]. Future work should substantiate the findings of this foundational work with a larger population of individuals with $\mathrm{BI}$. The standard error of measurement and MDC calculated in this study should only be used with individuals with similar characteristics, considering age, chronicity of injury, and functional abilities. 


\section{Conclusion}

Clinicians and rehabilitation researchers can use the DMA scores of the standardized Propriotest ${ }^{\circledR}$ reliably with community dwelling individuals who have experienced a severe traumatic $B I$ to determine whether a change in score represents a true effect of a balance-focused intervention at post-treatment and subsequent measures.

Disclosures The authors declare no conflicts of interest, including financial, consultant, institutional or any other conflict involving relationships that might lead to bias towards the submitted work.

Funding This study was funded, in part, by The Bill Kubly student research scholarship awarded to Thad W. Buster.

\section{References}

[1] Hillier SL, Sharpe MH, Metzer J. Outcomes 5 years posttraumatic brain injury (with further reference to neurophysical impairment and disability). Brain Inj. 1997;11(9): 661-675.

[2] Tefertiller C, Hays K, Natale A, et al. Results from a randomized controlled trial to address balance deficits after traumatic brain injury. Arch Phys Med Rehabil. 2019;100(8): 1409-1416.

[3] Cesar GM, Sigward SM. Dynamic stability during running gait termination: predictors for successful control of forward momentum in children and adults. Hum Mov Sci. 2016;48:37-43.

[4] Jacobs JV, Horak FB. Cortical control of postural responses. J Neural Transm. 2007;114(10):1339-1348.

[5] Takakusaki K. Functional neuroanatomy for posture and gait control. J Mov Disord. 2017;10(1):1-17.

[6] Tang PF, Woollacott MH. Inefficient postural responses to unexpected slips during walking in older adults. J Gerontol A Biol Sci Med Sci. 1998;53:M471-80.

[7] Cantin JF, McFadyen BJ, Doyon J, et al. Can measures of cognitive function predict locomotor behaviour in complex environments following a traumatic brain injury? Brain Inj. 2007;21(3):327-334.

[8] Carlson KF, Meis LA, Jensen AC, et al. Caregiver reports of subsequent injuries among veterans with traumatic brain injury after discharge from inpatient polytrauma rehabilitation programs. J Head Trauma Rehabil. 2012;27(1):14-25.

[9] Mansfield A, Schinkel-Ivy A, Danells CJ, et al. Does perturbation training prevent falls after discharge from stroke rehabilitation? A prospective cohort study with historical control. J Stroke Cerebrovasc Dis. 2017;26(10):2174-2180. 
[10] Yang F, Pai CY. Alteration in community-dwelling older adults' level walking following perturbation training. J Biomech. 2013;46(14):2463-2468.

[11] Agostini V, Chiaramello E, Bredariol C, et al. Postural control after traumatic brain injury in patients with neuro-ophthalmic deficits. Gait Posture. 2011;34(2):248-253.

[12] De la Casa-Fages B, Alonso-Frech F, Grandas F. Effect of subthalamic nucleus deep brain stimulation on balance in Parkinson's disease: a static posturographic analysis. Gait Posture. 2017;52:374-380.

[13] Howcroft J, Lemaire ED, Kofman J, et al. Elderly fall risk prediction using static posturography. PLoS One. 2017;12(2): e0172398.

[14] Lawrence EL, Cesar GM, Bromfield MR, et al. Strength, multijoint coordination, and sensorimotor processing are independent contributors to overall balance ability. Biomed Res Int. 2015;2015:1.

[15] Visser JE, Carpenter MG, van der Kooij H, et al. The clinical utility of posturography. Clin Neurophysiol. 2008;119(11): 2424-2436.

[16] Broglio SP, Sosnoff JJ, Rosengren KS, et al. A comparison of balance performance: computerized dynamic posturography and a random motion platform. Arch Phys Med Rehabil. 2009;90(1):145-150.

[17] Buster TW, Chernyavskiy P, Harms NR, et al. Computerized dynamic posturography detects balance deficits in individuals with a history of chronic severe traumatic brain injury. Brain Inj. 2016;30(10):1249-1255.

[18] Wrisley DM, Stephens MJ, Mosley S, et al. Learning effects of repetitive administrations of the sensory organization test in healthy young adults. Arch Phys Med Rehabil. 2007; 88(8):1049-1054.

[19] Hagen C, Malkmus D, Durham P. Levels of cognitive functioning. Rehabilitation of the head injured adult: Comprehensive cognitive management. Downey: Professional Staff Association of Rancho Los Amigos Hospital, Inc; 1979; 87-88.

[20] Myers AM, Powell LE, Maki BE, et al. Psychological indicators of balance confidence: relationship to actual and perceived abilities. J Gerontol A Biol Sci Med Sci. 1996;51: M37-43.

[21] Newstead AH, Hinman MR, Tomberlin JA. Reliability of the Berg Balance Scale and balance master limits of stability tests for individuals with brain injury. J Neurol Phys Ther. 2005;29(1):18-23.

[22] Peters DM, Jain S, Liuzzo DM, et al. Individuals with chronic traumatic brain injury improve walking speed and mobility with intensive mobility training. Arch Phys Med Rehabil. 2014;95(8):1454-1460.

[23] Myers AM, Fletcher PC, Myers AH, et al. Discriminative and evaluative properties of the activities-specific balance confidence (ABC) scale. J Gerontol A Biol Sci Med Sci. 1998;53: M287-294.

[24] Berg KO, Maki BE, Williams Jl, et al. Clinical and laboratory measures of postural balance in an elderly population. Arch Phys Med Rehabil. 1992;73(11):1073-1080. 
[25] Medley A, Thompson M, French J. Predicting the probability of falls in community dwelling persons with brain injury: a pilot study. Brain Inj. 2006;20(13-14):1403-1408.

[26] Shumway-Cook A, Baldwin M, Polissar NL, et al. Predicting the probability for falls in community-dwelling older adults. Phys Ther. 1997;77(8):812-819.

[27] Koo TK, Li MY. A guideline of selecting and reporting intraclass correlation coefficients for reliability research. J Chiropr Med. 2016;15(2):155-163.

[28] Weir JP. Quantifying test-retest reliability using the intraclass correlation coefficient and the SEM. J Strength Cond Res. 2005;19:231-240.

[29] Bland JM, Altman DG. Statistical methods for assessing agreement between two methods of clinical measurement. Lancet. 1986;1:307-310.

[30] Giavarina D. Understanding Bland Altman analysis. Biochem Med. 2015;25(2):141-151.

[31] Baratto L, Morasso PG, Re C, et al. A new look at posturographic analysis in the clinical context: Sway-density versus other parameterization techniques. Motor Control. 2002; 6(3):246-270.

[32] Prosperini L, Fortuna D, Gianni C, et al. The diagnostic accuracy of static posturography in predicting accidental falls in people with multiple sclerosis. Neurorehabil Neural Repair. 2013;27(1):45-52.

[33] Fioretti S, Scocco M, Ladislao L, et al. Identification of peripheral neuropathy in type-2 diabetic subjects by static posturography and linear discriminant analysis. Gait Posture. 2010;32(3):317-320.

[34] Barclay-Goddard R, Stevenson T, Poluha W, et al. Force platform feedback for standing balance training after stroke. Cochrane Database Syst Rev. 2004; 18;(4):CD004129.

[35] Navalon N, Verdecho I, Llorens R, et al. Progression of posturographic findings after acquired brain injury. Brain Inj. 2014;28:1417-1424.

[36] Broglio SP, Ferrara MS, Sopiarz K, et al. Reliable change of the sensory organization test. Clin J Sport Med. 2008;18(2): 148-154.

[37] Foster H, DeMark L, Spigel PM, et al. The effects of backward walking training on balance and mobility in an individual with chronic incomplete spinal cord injury: a case report. Physiother Theory Pract. 2016;32(7):536-545.

[38] Bonan IV, Colle FM, Guichard JP, et al. Reliance on visual information after stroke. Part I: Balance on dynamic posturography. Arch Phys Med Rehabil. 2004;85(2):268-273.

[39] Gofrit SG, Ilan O, Mayler Y, et al. The association between videonystagmography and sensory organization test of computerized dynamic posturography in patients with vestibular symptoms. Eur Arch Otorhinolaryngol. 2019.

[40] Nashner LM, Peters JF. Dynamic posturography in the diagnosis and management of dizziness and balance disorders. Neurol Clin. 1990;8(2):331-349. 
[41] Marchetti GF, Lin CC, Alghadir A, et al. Responsiveness and minimal detectable change of the dynamic gait index and functional gait index in persons with balance and vestibular disorders. J Neurol Phys Ther. 2014;38(2):119-124.

[42] Klima D, Morgan L, Baylor M, et al. Physical performance and fall risk in persons with traumatic brain injury. Percept Mot Skills. 2019;126(1):50-69. 